\title{
O MEIO ELETRÔNICO COMO ESPAÇO DE FALA PARA MULHERES NEGRAS
}

\author{
Caroline Rodovalho (Mestrado em Letras: Estudos Literários - UEL) \\ Prof. Dr. Miguel Heitor Braga Vieira (Orientador)
}

\section{RESUMO}

O presente artigo tem como objetivo analisar o processo de reconstrução identitária da mulher negra no Brasil e a utilização do meio eletrônico como espaço de divulgação de tais experiências em forma de relatos textuais. Trajetórias de formação e fortalecimento da identidade desse grupo de mulheres resultam em numerosos relatos encontrados em blogs ou portais na internet, ferramentas que permitem a livre expressão e facilitam $o$ acesso à leitura. $O$ portal Blogueiras Negras, espaço destinado à visibilidade da mulher negra na sociedade, é um espaço que reúne, entre outros textos, matérias e histórias pessoais de vida, cujos temas centrais são a mulher negra e dificuldades que permeiam seu processo de empoderamento. Ressaltam-se nessas narrativas o lugar ocupado por esse grupo na sociedade e problemáticas que envolvem desde a violência física ao preconceito, que compromete sua autoestima. Como objeto deste estudo nos debruçaremos sobre o texto "Nasci negra depois dos 30", escrito pela jornalista Shirlene Marques e publicado no portal em 2014, relato autobiográfico no qual se evidencia um processo de reconquista da auto estima por meio do resgate de elementos ligados à cultura afro-brasileira e da valorização de características físicas típicas da população negra.

Palavras-chave: Identidade; Mulher negra; Preconceito.

\section{INTRODUÇÃO}

O presente artigo pretende analisar o processo de construção da identidade e empoderamento da mulher negra em relatos presentes no meio digital, considerado um espaço de fala e divulgação de tais experiências. Grande parte dessas narrativas retomam um período de apagamento da identidade dessas mulheres e a negação, enquanto criança e adolescente, de características físicas relacionadas à negritude. Desta forma, pretendemos investigar o processo de reconstrução da identidade e da autoestima de mulheres negras a partir da reflexão acerca do histórico de desconstrução identitária do negro, da discriminação racial sofrida por mulheres negras e, por fim, de textos vinculados no meio eletrônico que sirvam como testemunho dessas experiências.

Primeiramente, teceremos um breve histórico da trajetória de apagamento da identidade do negro que remonta à escravização dos povos africanos e sua vinda para o Brasil. Desde então, a imagem do negro foi (e continuar a ser) constantemente relacionada à deficiência moral, marginalidade e desvio dos padrões estéticos vigentes (HOFBAUER, 2006). Verificaremos de que modo a segregação das populações negras contribuiu para a desconstrução da identidade desse grupo. 


\section{SEMINÁRIO DE PESQUISA EM CIÊNCIAS HUMANAS - SEPECH \\ Humanidades, Estado e desafios didático-científicos \\ Londrina, 27 a 29 de julho de 2016}

Em um segundo momento nos concentraremos na problemática da desconstrução da identidade da mulher negra. Como base, nos servirão os artigos de Sueli Carneiro, "Mulheres em movimento" (2003) e "Gênero raça e ascensão social" (1995). Nestes trabalhos a pesquisadora aborda, respectivamente, as lutas e conquistas de mulheres negras no movimento feminista e a reflexão sobre a suposta preferência de homens negros que ascendem socialmente por mulheres brancas. Neste sentido, o livro Mulher negra: afetividade e solidão, da pesquisadora Ana Claudia Lemos Pacheco, apresenta relatos de mulheres negras e suas experiências de reconstrução identitária e empoderamento que vão ao encontro das reflexões propostas por Sueli Carneiro e as complementam.

Por fim, analisaremos o texto "Nasci negra depois dos 30", publicado em 2014 pela jornalista Shirlene Marques no portal Blogueiras Negras. Neste relato, procuraremos destacar trechos que evidenciem o processo de apagamento da identidade da mulher negra e sua reconstrução por meio do contato com a cultura afro-brasileira e a valorização das características fenotípicas do indivíduo negro.

\section{IDENTIDADE NEGRA: UM BREVE PANORAMA DA DESCONSTRUÇÃO}

A pesquisadora Zilá Bernd, remetendo ao sociólogo Lévi-Strauss, defende que o conceito de identidade possui uma natureza abstrata, não podendo se resumir à simples alusão a alguns referentes empíricos (cor da pele, textura do cabelo etc). Assim, esses referentes por si sós não são suficientes para definir a identidade do indivíduo negro. Desta forma, a construção da identidade se baseia na visão do outro sobre o indivíduo e na junção de vários referentes empíricos (BERND, 1992).

Em vista disso devemos reconhecer que a problemática da formação da identidade do negro, de modo mais amplo, não se limita ao reconhecer-se negro e aceitar-se como tal. É preciso levar em conta séculos de desconstrução dessas identidades, seja no abandono, quando da diáspora negra e escravização, de seus costumes e crenças, seja na desvalorização de suas qualidades morais (o negro visto como indivíduo de índole duvidosa) e fenotípicas. Primeiramente, na condição de ser humano escravizado, o negro se via separado, muitas vezes, de sua família, fato que impossibilitava a continuidade e a manutenção de sua própria dinâmica de vida (BASTIDE, 1974). Restava-lhe apenas a opção de uma tentativa de integração ao modo de vida do grupo dominante e possibilidades incertas de ascensão social, tais como trabalhos de confiança na casa dos senhores de escravos ou mesmo a liberdade e a união a grupos de negros libertos. Todavia, tais possibilidades estavam disponíveis somente àqueles que "[...] aceitavam o cristianismo e os valores ocidentais, que renegavam, portanto, seus costumes e suas crenças ancestrais" (BASTIDE, 1974, p. 27). Estas mesmas alternativas não traziam a garantia de proteção ou aceitação por parte dos brancos. Como consequência, isolados em uma ordem social que não os acolhia, restou aos negros a construção de uma nova cultura como forma de se adaptar à realidade imposta pela segregação. Deste modo, dois aspectos são essências para se começar a compreender a problemática do processo de apagamento da identidade negra: o distanciamento da cultura de origem e o contato e aceitação forçada da cultura dominante.

Ao esclarecer o processo de fragmentação das identidades na atualidade, o sociólogo Stuart Hall (2005) discorre acerca de outro desdobramento dessa problemática: a 


\section{SEMINÁRIO DE PESQUISA EM CIÊNCIAS HUMANAS - SEPECH \\ Humanidades, Estado e desafios didático-científicos \\ Londrina, 27 a 29 de julho de 2016}

questão das identidades nacionais. Considerando a construção do conceito de identidade nacional um ideal imaginário, Hall põe em cheque a função dessa suposta ferramenta unificadora, que pretende erigir o ideal de nação. Segundo ele, devemos ter em mente que a cultura nacional é também uma estrutura de poder. Em resumo, uma cultura dominante sempre subjuga a cultura dominada, impondo-lhe sua própria dinâmica de funcionamento. Neste sentido, é imprescindível retomar as preocupações acerca da unificação da nação que, no início do século XX, deram origem às teorias racistas, como a proposta de branqueamento.

Para tornar-se unificada era antes necessário que a nação brasileira se tornasse branca. A meta do processo de branqueamento, teoria difundida no início do século XX pelo intelectual Oliveira Vianna era que, dentro de algumas gerações, após a miscigenação entre negros e brancos (sendo esta última "raça" superior e, portanto, portadora dos genes dominantes) a população se tornasse majoritariamente branca e que se amenizassem características negras mais evidentes (nariz achatado e largo, cabelos crespos e a cor da pele). Somente depois de concluído o processo a nação brasileira estaria unificada e poderia progredir (HOFBAUER, 2006). Malgrado o ideal de branqueamento da nação tenha sido deixado de lado e a principal pauta da atualidade seja a de aceitação das diferenças e respeito à individualidade e livre expressão, ainda hoje ser negro é sinônimo de marginalidade e não aceitação. Por isso, em lugar da ideia de uma cultura unificada deveríamos pensar, segundo Hall, em uma construção imposta, que ainda contém em seu cerne diferenças internas mescladas à ilusão de identidade nacional (HALL, 2006).

\section{MULHER NEGRA: PRECONCEITO E REJEIÇÃO}

Em seu artigo "Mulheres em movimento" (2003) a pesquisadora Sueli Carneiro tece um breve panorama das conquistas femininas no Brasil. A autonomia sobre seus próprios corpos, a luta contra a violência doméstica e sexual, a conquista de posições de destaque no mercado de trabalho são, dentre outros aspectos, são citados como ganhos indiscutíveis do movimento feminista no Brasil e no mundo. No entanto, Carneiro afirma que o movimento feminista brasileiro se encontrava ainda ligado a uma visão eurocêntrica e universalizante da mulher, deixando de reconhecer a problemática que permeia outros tipos de violência, como as que atingem mulheres negras, por exemplo. Daí a necessidade de dar maior visibilidade à mulher negra no interior do movimento feminista, afirmando e viabilizando "[...] uma perspectiva feminista negra que emerge da condição específica de ser mulher, negra e, em geral, pobre [...]" (CARNEIRO, 2003, p. 118). Desta forma, as mulheres negras podem, dentro do feminismo, concentrar-se em problemáticas ligadas à sua condição, como o preconceito de que são vítimas.

Para Sueli Carneiro, além da violência doméstica e sexual sofrida pela mulher, de modo geral, há ainda uma forma de violência que inibe a mulher negra no campo afetivo, no trabalho e rebaixa sua autoestima. Em seu outro artigo, "Gênero, raça e ascensão social" (1995), ao analisar o texto do escritor Joel Rufino dos Santos que discorre acerca de preferência de homens negros que ascendem socialmente por relações com mulheres brancas, a pesquisadora afirma que, além de construir um discurso machista em relação ao gênero feminino, Rufino manifesta uma ideia 


\section{SEMINÁRIO DE PESQUISA EM CIÊNCIAS HUMANAS - SEPECH \\ Humanidades, Estado e desafios didático-científicos \\ Londrina, 27 a 29 de julho de 2016}

preconceituosa em relação à visão que propõe da mulher negra: um "objeto" menos valorizado que a mulher branca . Não obstante, ambos partilham uma mesma visão acerca dos padrões de beleza vigentes na sociedade, pois, para Sueli Carneiro

[...] é verdadeiro que as mulheres negras são socialmente desvalorizadas em todos os níveis inclusive esteticamente como é verdadeiro também que as mulheres brancas constituem o ideal estético feminino em nossa sociedade (CARNEIRO, 1995, p 547).

Para a pesquisadora Ana Claudia Lemos Pacheco em seu livro Mulher negra: afetividade e solidão (2013), a questão estética exerce um papel importante para a mulher negra na aceitação de si mesma, podendo, nos casos em que a autoimagem é prejudicada pelo padrão imposto, resultar em auto-rejeição. Seu trabalho é baseado em entrevistas com mulheres negras, militantes do movimento negro ou não, que narram suas experiências familiares e afetivas da infância até a idade adulta. No relato de Clementina, empregada doméstica e ativista do movimento negro, a entrevistada narra a dificuldade em aceitar-se como mulher negra, dificuldade esta que remete tanto a suas características físicas (cor da pele, cabelo) quanto à relação que estabelecia com pessoas não negras. Há também relatos de mulheres negras que trabalham em grandes empresas como secretárias. São histórias de preconceito no local de trabalho, tanto em relação à estética dessas mulheres quanto ao ambiente, composto majoritariamente por pessoas brancas, onde a pressão por destacar-se e não errar é grande, no intuito de provar que a competência supera a discriminação racial.

Também os meios de comunicação ainda são falhos quanto à representatividade da mulher negra. Considerando a importância desses canais na construção da autoestima dessas mulheres, é de extrema importância aumentar a visibilidade desse grupo social. Malgrado avanços incontestáveis neste segmento (a presença de mulheres negras na mídia vem amentando consideravelmente na atualidade) os papéis reservados a elas em folhetins televisivos, por exemplo, ainda são ligados ao trabalho doméstico ou a hipersexualização de seus corpos (CARNEIRO, 2003).

Podemos concluir que, em uma sociedade onde o padrão de beleza valoriza mulheres brancas e de características físicas eurocêntricas, não restam à mulher negra muitas alternativas que enalteçam suas próprias características físicas e suas potencialidades.

\section{O MEIO VIRTUAL COMO ESPAÇO DE FALA: BLOGUEIRAS NEGRAS.}

Idealizado inicialmente como um veículo de divulgação para textos que discutiam as datas do Dia da Consciência Negra (20 de novembro) e Dia internacional de combate à violência contra as mulheres (25 de novembro), o portal Blogueiras Negras está em atividade desde o ano de 2012. O portal pretende reunir em um espaço comum de troca de informações mulheres negras das mais diversas áreas (sociólogas, estudantes, publicitárias etc) no intuito de difundir a cultura negra onde a representação feminina se faz presente. A questão da representatividade da mulher negra é de extrema importância para as mulheres que o utilizam o portal como espaço de fala (NUNES, 2015). No sentido de legitimarmos a importância do meio digital na difusão de conhecimento e literatura, recorremos o pensamento de Walter Benjamin. Para o filósofo, ao apropriar- 


\section{SEMINÁRIO DE PESQUISA EM CIÊNCIAS HUMANAS - SEPECH \\ Humanidades, Estado e desafios didático-científicos \\ Londrina, 27 a 29 de julho de 2016}

se dos meios de distribuição de informação (neste caso os portais de conhecimento) o autor, além de tornar-se independente das formas mais convencionais de divulgação de seu trabalho, estabelece uma relação de grande proximidade com o proletariado e também com outros produtores (BENJAMIN, 1993). Dessa maneira, em sua função de reunir e difundir informação e material literário, o portal Blogueiras Negras, ao mesmo tempo em que aproxima o leitor facilita a divulgação de trabalhos de autores que podem estabelecer entre si uma rede de troca de conhecimento e partilhar vivências.

Analisaremos o texto "Nasci negra depois dos 30", publicado no portal Blogueiras Negras pela jornalista Shirlene Marques em junho de 2014. O texto da jornalista narra, de sua infância até a idade adulta, o processo de desconstrução que sofreu e, por fim, a identificação com a origem negra que possibilitou a reestruturação de sua autoimagem. Sua busca por autoaceitação enquanto mulher negra perpassa caminhos que vão desde símbolos de branqueamento (a religião católica, os cabelos alisados, o distanciamento experimentado em relação à cultura africana) até, finalmente, o reencontro com a religião de matriz africana e a recuperação da autoestima, ao abandonar os procedimentos de alisamento dos cabelos aos quais se submetia (MARQUES, 2014).

Em seu relato, Shirlene Marques retoma a infância e juventude, épocas onde era considerada, por si e pelos outros, uma pessoa branca ou, no máximo, mesmo morena clara. Adepta da religião católica, a jornalista permanecia em constante luta contra as características físicas que evidenciavam suas origens negras:

[...] saí da infância lutando para negar marcas genéticas, como o tipo de cabelo. Cabelo este que eu considerava ruim e difícil de manter-se domado, dominado. Afinal, os outros reproduziam e insistiam: "cabelo ruim é assim mesmo" (MARQUES 2014).

Percebe-se o discurso discriminatório que nos remete aos textos de Sueli Carneiro, onde a pesquisadora ressalta força da hegemonia do padrão estético eurocêntrico como ideal de beleza e, consequentemente, a desvalorização das características físicas da mulher negra (CARNEIRO,1995). Também é necessário recordar que esta desconstrução e depreciação do corpo do negro ocorre desde o período escravista, como afirma Hofbauer pois,

Chamar a atenção para a cor de pele escura (ou "traços raciais negroides") de alguém era uma grande ofensa, sobretudo para aqueles que buscavam ascender socialmente (HOFBAUER, 2006, p. 177).

Ao aproximar-se da adolescência, a jornalista relata que não se considerava bela devido às características físicas que remetiam à sua origem negra. Para ela, as "Missas e alisamentos colocavam a herança negra bem longe de mim; era um mundo de apreciação" (MARQUES, 2014). Portanto, a cultura negra era, para Shirlene, apenas um universo distante a ser apreciado e não um elemento concreto que pertencesse a suas origens.

Somente após o ingresso na faculdade de jornalismo e o envolvimento, mesmo que apenas emocional, com as lutas e conquistas de mulheres e homens negros começa uma mudança na autoimagem de Shirlene, que se fortalece após sua iniciação no Candomblé. Juntamente com o contato com o Candomblé e a reflexão sobre sua própria origem veio à consciência de ser negra. Ao final de seu relato, Marques afirma: "Tenho nariz 


\section{SEMINÁRIO DE PESQUISA EM CIÊNCIAS HUMANAS - SEPECH \\ Humanidades, Estado e desafios didático-científicos \\ Londrina, 27 a 29 de julho de 2016}

achatado, cabelo crespo, lábios grossos, sangue negro em minhas veias [...]" (MARQUES, 2015).

\section{CONCLUSÃO}

Ao retomarmos e analisarmos o histórico de desconstrução da identidade do negro desde o período escravista até os dias atuais, compreendemos as dificuldades de retomada e conquista da auto estima por parte de homens e pincipalmente mulheres negras. Constatamos que estratégias de depreciação ocorriam de forma a dificultar ou mesmo impedir a inserção do negro recém-liberto na sociedade. Excluído do projeto de unificação da nação, vítima de ideias racistas como a do branqueamento da população brasileira, o negro teve de reconstruir dentro de suas possibilidades uma dinâmica de vida que possibilitasse sua sobrevivência em meio à nova realidade à qual foi forçado a integrar.

Para as mulheres negras, além de problemáticas que permeiam a violência sexual e doméstica, a precariedade do acesso à saúde de qualidade, dentre outras dificuldades, a discriminação é uma forma de violência que fere e segrega. A cor da pele, os cabelos crespos e outras características físicas que as identificam como negras fecham as portas do mercado de trabalho e podem também dificultar as relações afetivas. $\mathrm{O}$ apagamento de suas raízes é a saída que muitas mulheres negras encontram para se encaixar em padrões estéticos arbitrários.

O processo de reconstrução da identidade da mulher negra passa por etapas de auto aceitação e de identificação com a cultura afro. No relato de Shirlene Marques é evidente que a aproximação e apropriação de elementos culturais afro-brasileiros, em especial a religião, proporcionaram à jornalista maior contato com sua própria e historia e, consequentemente, possibilitaram a reconstrução de sua identidade agora profundamente atrelada à suas origens negras.

\section{BIBLIOGRAFIA}

BASTIDE, Roger. As Américas negras: as civilizações africanas no novo mundo. Tradução de Eduardo Oliveira e Oliveira. São Paulo: Difel, 1974.

BENJAMIN, Walter. O autor como produtor. In: Magia e técnica, arte e política: ensaios sobre literatura e história da cultura. Tradução de Sergio Paulo Rouanet. São Paulo: Brasiliense, 1993.

BERND, Zila. Literatura e identidade nacional. Porto Alegre: Editora da Universidade Federal do Rio Grande do Sul, 1992.

CARNEIRO, Sueli. Gênero, raça e ascensão social. Estudos Feministas, Florianópolis, v. 3, n. 2, p. 544-552, 1995.

Mulheres em movimento. Estudos avançados, São Paulo, v. 17, n. 49, p. 117133, 2003. 


\section{SEMINÁRIO DE PESQUISA EM CIÊNCIAS HUMANAS - SEPECH \\ Humanidades, Estado e desafios didático-científicos \\ Londrina, 27 a 29 de julho de 2016}

HALL, Stuart. A identidade cultural na pós-modernidade. Tradução de Tomaz Tadeu da Silva e Guaracira Lopes Louro. Rio de Janeiro: DP\&A, 2005.

Da diáspora: Identidades e mediações culturais. Tradução de Adelaide la Guardia Resende et al. Belo Horizonte: Editora UFMG, 2006.

HOFBAUER, Andreas. Uma história de branqueamento ou o negro em questão. São Paulo: Editora Unesp, 2006.

MARQUES, Shirlene. Nasci negra depois dos 30. 2014. Disponível em: $<$ http://blogueirasnegras.org/2014/06/19/nasci-negra/>. Acesso em: 18 set. 2015.

NUNES, Charô. Quem Somos: Reinventando a tela. Disponível em: http://blogueirasnegras.org/quem-somos/. Acesso em: 17 set. 2015.

PACHECO, Ana Cláudia Lemos. Mulher negra: afetividade e solidão. Salvador: ÉDUFBA, 2013. 